\title{
Exploring Sustainable Development and Its Interpretation in the Built Environment
}

\author{
Bilge Gokhan Celik ${ }^{1}$ \\ ${ }^{1}$ School of Engineering, Computing and Construction Management, Roger Williams University, Rhode Island, \\ USA
}

Correspondence: Bilge Gokhan Celik, School of Computing and Construction Management, Roger Williams University, Bristol, RI, USA. Tel: 1-401-254-3648. E-mail: bgcelik@rwu.edu

Received: October1, 2013 Accepted: November 11, 2013 Online Published: November 26, 2013

doi:10.5539/jsd.v6n12p83 URL: http://dx.doi.org/10.5539/jsd.v6n12p83

\begin{abstract}
Building industry is a significant contributor to a majority of environmental issues. Design, construction, operation and disposal of buildings and cities also impact social and economic standards. Building industry's triple and high interaction with the human development requires professionals within the industry to reevaluate their development approaches. This requires designers such as architects and engineers, as well as the builders to understand the basics of sustainable development and how it has been and can be incorporated into their professions. Many resources in this area focus on the technical aspect of sustainability as an effort to train professionals in sustainable applications. However, sustainability is a more complicated concept that evolves based on time, location, and intent. Thus it is critical for building professionals to evaluate sustainability and sustainable development at a conceptual level, which can allow them to make better decisions in a continuously changing global world. This paper introduces the philosophical concepts behind sustainability in the built environment and specifically focuses on the role of builders, designers, and owners in the implementation of these concepts.
\end{abstract}

Keywords: built environment, ecological buildings, sustainability, globalization, regionalization

\section{Introduction}

Sustainability has been a major concern for many industries including the building industry. Achieving sustainability of a building requires a shift in decision making throughout the entire life cycle of a building including its design, construction, operation, and disposal. Starting with the building owners, many parties involved in the creation of the built environment have become to realize that the only way to fully achieve the principles of sustainability is to work towards it as a team. A typical list of participants in the building industry includes the client (owner), designer (architects and engineers), constructors (builders), public officials, and the public.

One of the many challenges that the project teams face is to determine how to measure the success of the end product and its construction process. This challenge is also known as the determination of a sustainability rating. Although there is still not a single global source for a sustainability building rating system (Ding, 2008), there have been many successful efforts at regional, national, and international levels (Reed, Bilos, Wilkinson, \& Schulte, 2009). Two of the most popular and widely used rating systems are the Leadership in Energy and Environmental Leadership (LEED) developed by USGBC, and Building Research Establishment's Environmental Assessment Method (BREEAM).

Creating a sustainable built environment can be a challenging task for a project team. However, a bigger challenge is to understand the basic concepts of this global effort. It is the role of educators in the associated disciplines to introduce the philosophy behind the term "Sustainable Buildings", before providing them with the tools to achieve it. There is a clear need for more pedagogical resources in the schools of architecture, engineering, construction science/technology/management. This need is primarily to assist the instructors educate, inform, and train their students in becoming aware of the current issues as well as to help students be a part of this evolution as innovators of new, more efficient, higher quality, and conscious technologies. 
This paper introduces the basic philosophical concepts related to sustainable buildings and specifically focuses on the role and responsibilities of designers, builders, and building owners. It explores a bigger picture for the readers to create a personal and professional connection with their built environment and the associated sustainability related issues in a rapidly globalizing world.

\section{Global Forces Shaping the Built Environment}

Human beings have always had a mental and physical relationship with their environment (Celik, 2006). This relationship has been regulated by many internal and external forces, which in return shape the built environment around us. We as individuals or groups such as families, neighborhoods, citizens, and nations can generate internal forces. External forces on the other hand, include the natural and environmental factors such as the climate, weather patterns, topology, resources, etc. All of these factors, both internal and external, have major influences in the way humans design, construct, operate and dispose their built environment. Traditionally structures are initiated as a response to humans' need for shelter, and/or some utility to help them enjoy the seemingly endless features of the earth. Historically humans are known to consider buildings as a way to adapt to their natural settings. This has always included concerns for security, comfort, and functionality. The relation of humans with buildings, in the context of these concerns is essentially related to the essence of architecture and building construction (Celik, 2006). Fitch and Bobenhausen (1999) define the ultimate task of architecture as to act in favor of human beings. They state that the purpose of architecture is to maximize our capacities by permitting us to focus our limited energies upon those tasks and activities that are the essence of the human experience (Fitch \& Bobenhausen, 1999). It is about time we start reevaluating the purpose of architecture, and building construction.

None of the services embedded in a building can be achieved without the help of the resources that are already present in our natural environments. Prior to achieving the current levels of global interaction, buildings were being designed, built and operated with an understanding that they can only keep functioning if they become an integral part of the natural cycle and the environment that surrounds them. Interestingly humans, prior to gaining a broader knowledge of the earth's capacities and boundaries, have molded better into their surroundings. Vernacular architecture presents successful examples of this integration (Figure 1) (Note 2).

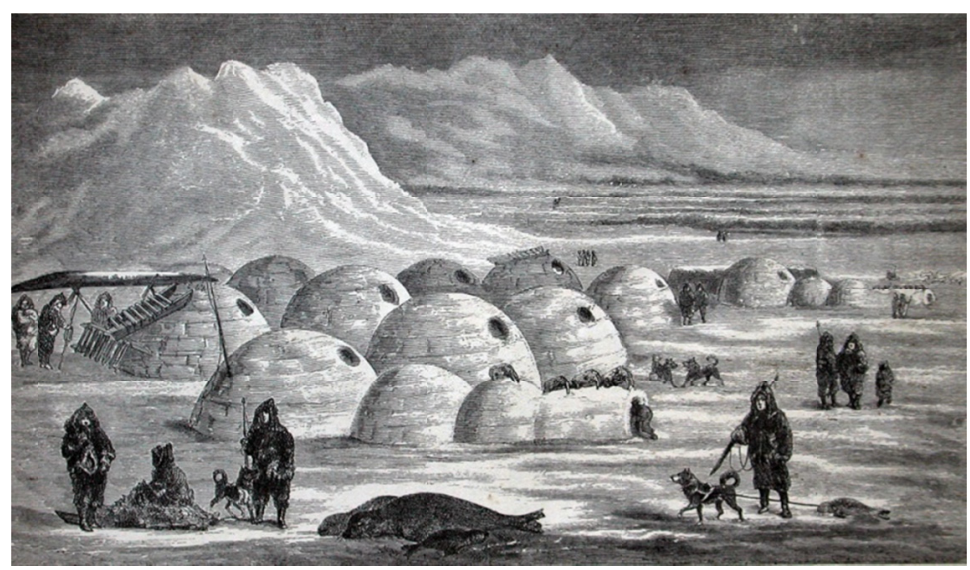

Figure 1. Historical design for the Eskimo igloo (Hall, 1865)

Increasing the understanding of the earth's boundaries have started humans to further eject themselves from it, as if the chances of survival depended on the independence from the forces that shape the environment. One of the causes of this confusion derives from a lack of understanding about the definitions and applications of terms "science" and "technology". According to Heidegger (1976), science deals with the natural world where technology is the study of the natural laws, which govern the universe. He states that science deals with "understanding" while technology deals with "doing". Keeping this definition in mind, it appears that contemporary design and construction increased their dependency on the earth's limited resources to increase the level of technology utilized in the built environment. In modern times, this dependency has far exceeded the level of science (understanding) behind the applied technologies (doing) (Figure 2). This resulted in over-utilization of non-renewable resources, which in return has been making our society less sustainable and 
more susceptible on the existence of these non-renewable resources. In order to understand this dilemma better, it is important to first understand the meaning of, and the philosophy behind the term "sustainability".

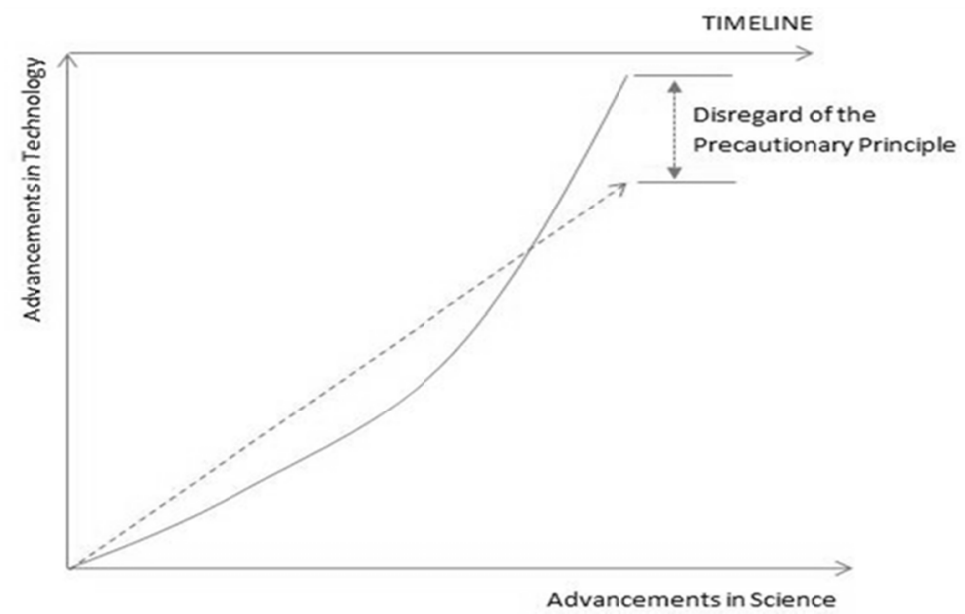

Figure 2. Science vs. technology in the timeline of the building industry

'Sustain' comes from the Latin sustenare, meaning to keep or hold up (Silverman, 2009). Dictionaries provide more than ten meanings for sustain, most common ones being to "maintain", "support", or "endure". However since 1980s, the term "sustainability" has been used mainly to describe the ability of the human race to maintain its existence in the planet Earth. This understanding generated another term called "sustainable development". One of the most popular definitions of sustainable development is a quote from Brundtland Commission of United Nation in 1987 where sustainable development is defined as the "development that meets the needs of the present without compromising the ability of future generations to meet their own needs" (United Nations, 1987). The UN's definition highlights two main goals that need to be well examined before determining the means and methods of achieving sustainable development. These are:

* Needs of the present

* Ability of future generations to meet their own needs

\subsection{Needs of the Present}

Dividing the definition of sustainable development into two main goals helps further clarify the efforts to achieve them. Based on the progress made by the past generations it appears as humans have achieved to invent technologies to meet their basic needs. Most of these technologies that are utilized in the building industry aim to create a secure, functional and comfortable built environment. However, while some societies achieved this goal, some still are struggling with creating a similar environment, which meets their basic needs. Reasons can be speculated in many ways by going deeper into political, sociological, environmental, economical, and historical aspects of the problem.

Even in the evaluation of only the developed countries, it is difficult sometimes to find sufficient proof of achieving the initial goal of sustainable development. This can be discussed from a point of view that one of the needs of the present is to live in a healthy environment. It has been continuously proven that many of us do not have that need met by the buildings we live in. Only until 20 years ago, building and health industries have started to research and take action on issues such as sick building syndrome (SBS), and building related illnesses (BRI) that are tied to various indoor air quality (IAQ) issues (Note 1). It is now becoming apparent in even more recent years that a healthy environment may include more than just an acceptable IAQ. Building experts and the general public are finally approaching to an understanding that the needs of the present can include but is not limited to:

* Safety and security (Preiser, 1995)

* Basic functionality (Vijverberg, 2002)

* Ergonomics (Koningsveld \& Van Der Molen, 1997)

* Indoor air quality (Sundell, 2004) 
* Thermal comfort (Höppe, 2002)

* Access to natural lighting (Edwards \& Torcellini, 2002)

* Access to views of nature (Kaplan \& Kaplan, 1989)

- Acoustical comfort (Kupritz, 1998)

* Odor control (Knasko, 1992)

There is not a single day that we do not discover some other mystery of what needs of the present are. Some of these discoveries impact the general building theme dominating the design and construction industry (Table 1) while some still are struggling to make a significant impact on the way buildings are designed, constructed, and operated. A good example of a relatively new concept that has a potential to impact the built environment is called Biophilia. Wilson (1984) introduced the hypothesis that there is an instinctive bond between human beings and other living systems. According to Wilson (1984), the term biophilia describes "the connections that human beings subconsciously seek with the rest of life." In his book, Wilson (1984) proposed that there might be deep affiliations between humans and the nature, which are rooted, in human biology.

Table 1. Historical quest for building quality. (Adapted from Chan, Burnett, \& Jones, 2000)

\begin{tabular}{lll}
\hline Decade & Issues & Building Theme \\
\hline $1960 \mathrm{~s}$ & Sense of coolness & Air-conditioning \\
$1970 \mathrm{~s}$ & $\begin{array}{l}\text { Energy crisis } \\
\text { Awareness of the SBS, and BRI, and application } \\
\text { of computer technology in buildings }\end{array}$ & $\begin{array}{l}\text { Energy efficient buildings } \\
\text { Intelligent buildings }\end{array}$ \\
& $\begin{array}{l}\text { Concern about the SBS, BRI and environmental } \\
\text { impacts }\end{array}$ & Healthy buildings \\
$1990 \mathrm{~s}$ & Global effort for sustainable development & Sustainable buildings \\
\hline
\end{tabular}

Meeting the needs of the present is undoubtedly a significant part of sustainable development. It is however important to determine exactly what those needs are and how they can be met. It is also important to realize that meeting the needs of the present, does not guarantee achieving sustainable development all by itself. Next section discusses the second goal of sustainable development: "Ability of future generations to meet their own needs".

\subsection{Ability of Future Generations to Meet Their Own Needs}

Based on the UN's definition of sustainable development, humans must be concerned with the ability of future generations to meet their own needs. The philosophy behind this concern can be better understood by thinking about the needs of the underrepresented groups. These groups can include people of various genders, races, nationalities, ages, religions, and people with disabilities. For example, women in many countries around the world still face discrimination where they do not hold the rights to vote or express their opinions on issues that directly shape the environment they live in. This problem also exists in some parts of the world for different races, people of certain religions, status and nations. Age and disabilities can also be determining factors for individuals to gain the right to express their opinions, and even determine their right to vote on alternative decisions that may impact their own living environment. Groups without these rights may include children as well as individuals with mental disabilities. It should then become the responsibility of those who have the right and the opportunity, to consider those without the same, when making and implementing decisions that influence the way humans live in and utilize the world.

As much as we care about our children and are concerned with their future, we should also consider those who are not born yet while consuming the resources that they will need as much as, or more than we do today to satisfy our basic needs. This can be achieved by considering basic sustainability principles within our decision-making processes. Some of these principles are the "precautionary principle", "irreversibility principle", and "polluter pays principle" (Kibert, 2012). These principles have officially been around (some claim since 1800s), and have somehow impacted the way humans introduced and advanced new technologies.

A good example of how to apply basic sustainability principles can be derived from a discussion around nuclear research and its applications. Although the efficiency of nuclear technology is proven to be much higher then 
many of the current energy generating technologies, it is still a concern within the minds of the many, on whether this technology is applicable when some of the principles mentioned above are taken into consideration. Precautionary principle requires decisions to be made to not to embrace certain actions or technologies when the exact consequences of these actions or technologies are not completely known (See Figure 2). Irreversibility principle requires humans to avoid decisions that are not reversible by future generations. Polluter pays principle requires the parties who are responsible for a certain decision, which may have generated negative outcomes, to be responsible for correcting the associated negative consequences of their decisions (Kibert, 2012).

Another perspective on the responsibility of the current society relates to resources and their current rate and type of uses. It is evident that currently our society is extremely dependent on the fossil fuel resources. These resources are also known as nonrenewable energy sources mainly due to the fact that it takes hundreds of millions of years for the earth to generate them, while the human consumption rate is significantly higher. It is mathematically proven many times that the humans will soon run out of major non-renewable resources (Shafiee \& Topal, 2009). Unfortunately, similar to many other industries, building industry is also heavily dependent on nonrenewable energy sources. This dependence derives from not only the energy that is being used within the buildings, but also the amount required for the building materials to be extracted, processed, transported, installed, and recycled or disposed by the end of their life cycle. This dependence is pushing the current building and construction technologies to a point where they soon will become void leaving future generations a world that is simply full of impractical amenities, technologies, and loads of waste.

Global issues shaping the built environment are not limited to energy and resource problems. "Meeting the needs of the present while maintaining the ability of future generations to also meet theirs" requires more than just sustainable and fair resource management. It requires attention to many other global issues. Although it may appear as, many of these issues do not relate to the building environment, understanding the concept of sustainability would require all industries to take part in the solution. This includes the building industry as well. A very good theory for understanding the relations between many different industries is called industrial ecology. Industrial ecology can be defined as "systems-based, multidisciplinary discourse that seeks to understand emergent behavior of complex integrated human/natural systems" (Allenby, 2006). A good example of applied industrial ecology is Eco-industrial Park in Kalundborg, Denmark. The network of companies located in the park collaborates to use each other's by-products and share resources. Eco-industrial Park includes a $1500 \mathrm{MW}$ coal fired power plant, with supply and demand connections in the community and with several other companies. Excessive waste heat from the plant is used to heat thousands of homes in the region as well as local establishments such a fish farm, which sells its waste as fertilizer. Power plant also generates steam, which is sold to a pharmaceutical and enzyme manufacturer, in addition to another energy plant. Additionally, a by-product from the power plant includes gypsum that is sold to a drywall manufacturer. Finally, fly ash and clinker from the power plant is utilized in road building and cement production (Ehrenfeld \& Gertler, 1997). Figure 3 illustrates the general concept of symbiosis and the closed loop cycle achieved by industrial ecology.

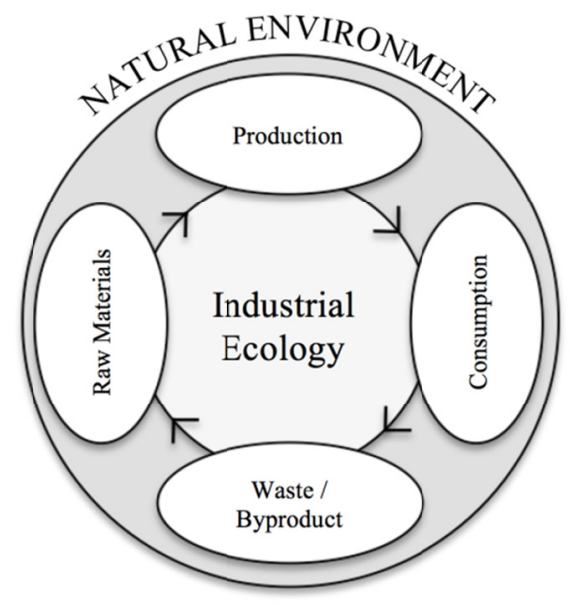

Figure 3. Symbiotic relationships within the concept of industrial ecology 
Concepts such as industrial ecology could be implemented into building industry. These complex but considerate symbiotic relations can be the answer for achieving sustainability in the built environment in a fashion to meet our needs and assuring that the future generations can do the same. In order to accomplish this, it is important to review the way building industry has been functioning, what its goals have been, and how the means and methods used so far can be modified for better and continuous results. Figure 4 illustrates an analysis of conventional building industry and how it can be modified towards an ecologically integrated and innovative level over time through various phases.

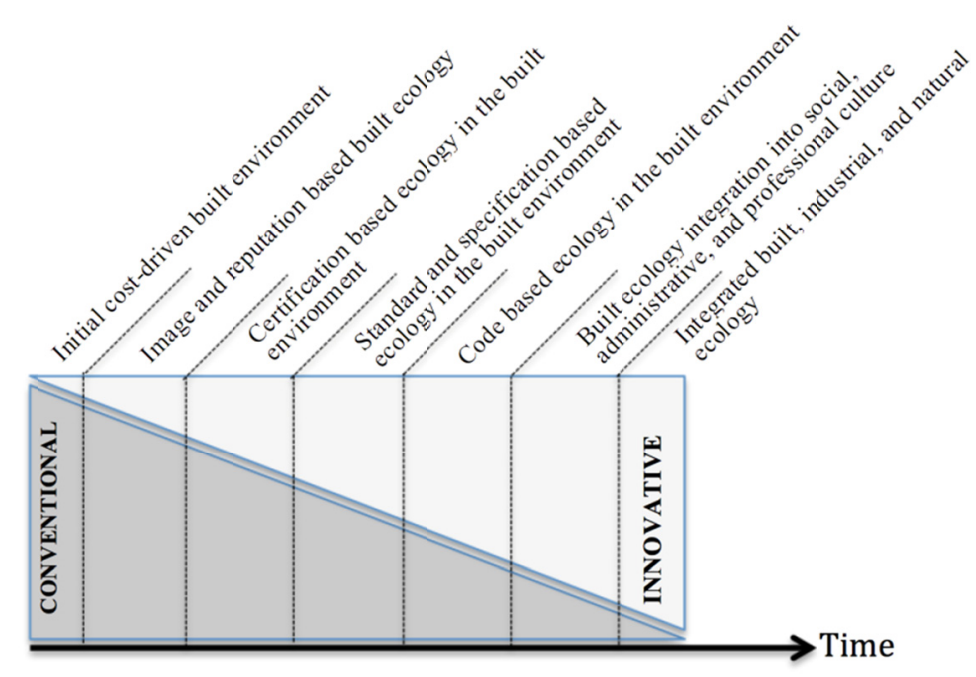

Figure 4. The emergence of an integrated ecology in an innovative built environment

This study mentioned some of the major global issues that shape the way in which the built environment and its utilities are designed, constructed, and disposed. Some of the examples of the other global issues that sustainable development focuses on, and are relevant to various other industrial practices, are given below. It is important to understand that the below list is not a complete one, and that other forces are being recognized as the concern and awareness for a fair and sustainable development increase among various industries.
* Global and regional poverty
* Women issues
* Diminishing food sources
* Global warming
* Diminishing water resources
* Biological diversity
* Air pollution
* Transportation

Sustainability concerns such as the ones listed above can also be used as sustainability indicators as long as they can be measured. Further information and a wider range of sustainability indicators can be found in Bell and Morse (2008).

\section{Globalization vs. Regionalization}

Globalization has become a common word in our lives mainly due to the fact that the borders of countries have become increasingly more transparent in the past century. There are many developments including technological advancements, which have been fueling globalization. Invention of technologies that make air transportation a possibility, allows the modern societies to travel between two different continents within less than a day. Privileged people of our century have an option to travel to a different country, observe the local and regional differences, and return back to their countries with many interesting stories to tell. These stories can be about a certain type of ceramic tile from Italy, or the bamboo walls that Chinese have been using in their traditional 
buildings for many centuries. It is then this information, which can easily travel around the world seeking and finding application grounds in various forms and locations.

Globalization of information has become even faster with the introduction of Internet into our lives. Internet, for the first time in the history of human beings, provides a fast, cheap, and convenient way to reach a variety of information. It is now possible for current generations to turn their computers on and see exactly what and how various nations are designing, building, and operating. It appears so far that at the rate which current generations are utilizing the Internet, import and export of authentic building materials among different regions of the world are also increasing. This increase is adding a significant workload on the shipping industry in which the public now has the ability to order building materials within a matter of few seconds over the Internet by providing a credit card number and a shipping address. Increased demand on the shipping and handling services created competition in the shipping industry thus helped decrease the prices of their services. The reduction or the sharing of these transportation costs have reached to a very reasonable price level that currently many building materials can be imported for cheaper than or for the same price as their regional equivalences. This mutation in the balances of globalization became possible mainly due to the fact that our economic framework has not had the time to react and adapt to the rapid changes brought by the increased levels of globalization. This can be explained due to the fact that traditional economies have failed to represent the true costs of products with an assumption that the economy can be thought independently from the natural environment. Even if the costs were not completely independent from the environment, they were calculated with a misunderstanding that the resources used to produce them were infinite. This resulted in cheaper costs for transportation and raw materials.

Recent sustainability movements and initiatives along with the help of increased awareness of the material and energy reserves of the world, have initiated the shift in moving towards newer methods of pricing materials and services. Building industry needs to, and slowly is, moving towards utilization of more comprehensive cost and environmental analysis tools such as Life Cycle Costing (LCC) and Life Cycle Analysis (LCA). LCC and LCA combined with other sophisticated decision-making tools (i.e. Analytical Hierarchical Process (AHP), Neural Networks, Decision Trees, and etc.) can be the solution to increasing the efficiency of material and energy related decisions in the building industry.

A better understanding of sustainable development in the recent years have started to shift the way experts look at the relations between social, environmental, and economic aspects of the modern world. The timeline of a changing understanding between these concepts is given in Figure 5.

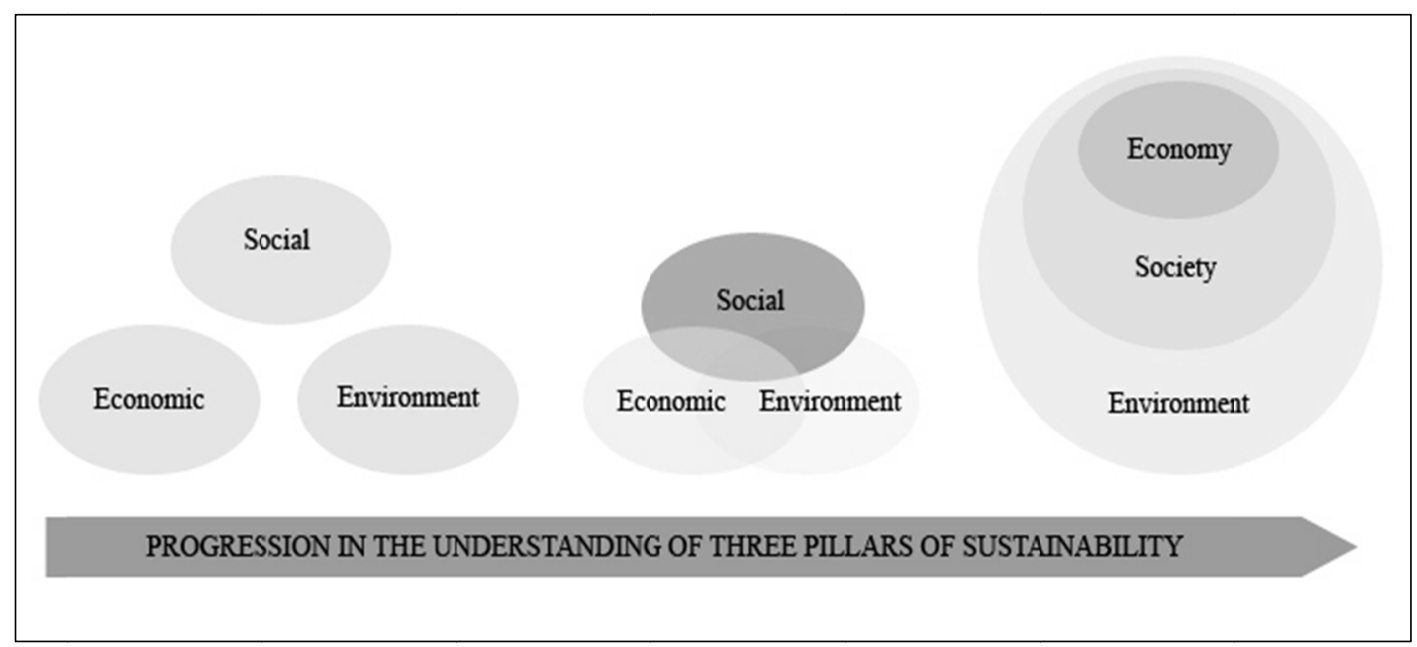

Figure 5. Understanding of social, economic, and environmental constraints within sustainability efforts

In order to understand the differences between globalization and regionalization, we can look at some dictionary definitions. Globalization can be defined as the development of an increasingly integrated global economy marked especially by free trade, free flow of capital, and the tapping of cheaper foreign labor markets (Merriam-Webster, n.d.). Regionalization on the other hand can be defined as the tendency to form regions or the process of doing so which when used in opposition to globalization, means a world that is less connected, with a stronger regional focus (Merriam-Webster, n.d.). Although regionalization sounds more radical and unusual 
especially compared to what globalization stands for, it would not be too difficult for one to realize that in order to achieve a sustainable globalization, regional solutions and systems need to be utilized. Eisenberg and Reed (2003, p. 7) state that when resources and sinks (where our needs come from and where they go to) are not local, the costs of procurement and waste disposal become inordinately high. Regionalization would allow industries to visualize and experience their impacts first hand thus take corrective actions. It is currently difficult for anyone to understand what the exact consequences of their actions are when many of the components within those actions come from other regions and countries.

A hypothesis can be that if humans were to achieve true sustainable regional living frameworks, globalization could also be achieved in a similar format. Sustainable globalization could be possible via increasing integration of sustainable regions.

A sustainable building industry will need true regionalization of materials and resources while globalizing even more when it comes to information and innovation. Achieving this will only be possible by utilizing regional materials in the design and construction of the buildings. Regional materials can be a complicated terminology in these times where most of the raw materials come from, processed, and assembled at different locations. Regionalization of materials and resources would require as many of these processes to be completed within the local reach. This would enable not only a reduction in transportation requirements and associated emissions, but also help the industry understand the limits of resources better than shopping at a global scale.

\section{Summary and Conclusion}

Principles of sustainable development require the current generations to meet their own needs without compromising the ability of future generations to do the same (United Nations, 1987). Building industry, a significant contributor to the environmental problems, needs to evaluate these relatively new principles and how they can be applied within. The solution will derive from a collaborative effort between various industries, policy makers, professionals, and the general public. The process will include reconsideration of philosophies and technologies within the current economy, and the society with an understanding that both are subject to the limits of the environment. Realizing the boundaries was the first step toward a more sustainable future. Now it is time for humans to proceed with the remaining steps to truly achieve sustainability for both current and future generations.

\section{References}

Allenby, B. (2006). The ontologies of industrial ecology. Progress in Industrial Ecology, 3(1), 28-40. http://dx.doi.org/10.1504/PIE.2006.010039

Bell, S., \& Morse, S. (2008). Sustainability indicators: measuring the immeasurable? Earthscan.

Celik, B. G. (2006). Decision Model to Optimize Indoor Air Quality in Commercial Buildings in Florida (Doctoral dissertation, University of Florida).

Chan, D. W., Burnett, J., \& Jones, P. (2010). Design for Building Environmental Performance. In W. S. Wong \& E. H. W. Chan (Eds.), Building Hong Kong: Environmental Considerations (pp. 151-182). Hong Kong: Hong Kong University.

Ding, G. K. (2008). Sustainable construction-the role of environmental assessment tools. Journal of Environmental Management, 86(3), 451-464. http://dx.doi.org/10.1016/j.jenvman.2006.12.025

Edwards, L., \& Torcellini, P. A. (2002). A literature review of the effects of natural light on building occupants. Golden, CO: National Renewable Energy Laboratory. http://dx.doi.org/10.2172/15000841

Ehrenfeld, J., \& Gertler, N. (1997). Industrial Ecology in Practice. The Evolution of Interdependence at Kalundborg. Journal of Industrial Ecology, 1(1), 67-79. http://dx.doi.org/10.1162/jiec.1997.1.1.67

Eisenberg, D., \& Reed, W. (2003, December 13). Regenerative design: toward the re-integration of human systems. A contribution to the City of Boston's Mayor's Green Building Task Force .

Fitch, J. M., \& Bobenhausen, W. (1999). American Building: Environmental Forces That Shape It. New York: Oxford University Press.

Hall, C. F. (1865). Arctic Researches and Life Among the Esquimaux: Being the Narrative of an Expedition in Search of Sir John Franklin in the Years 1860, 1861, and 1862. New York: Harper and Brothers. http://upload.wikimedia.org/wikipedia/commons/7/75/Igloos.jpg

Heidegger, M. (1976). Basic Writings from Being and Time to the Task of Thinking. New York: Harper \& Row. 
Höppe, P. (2002). Different aspects of assessing indoor and outdoor thermal comfort. Energy and buildings, 34(6), 661-665. http://dx.doi.org/10.1016/S0378-7788(02)00017-8

Kaplan, R., \& Kaplan, S. (1989). The experience of nature: A psychological perspective. CUP Archive.

Kibert, C. J. (2012). Sustainable Construction: Green Building Design and Delivery (Vol. 3). Hoboken, NJ: Wiley.

Koningsveld, E. A., \& Van der Molen, H. F. (1997). History and future of ergonomics in building and construction. Ergonomics, 40(10), 1025-1034. http://dx.doi.org/10.1080/001401397187586

Knasko, S. C. (1992). Ambient odor's effect on creativity, mood, and perceived health. Chemical Senses, 17(1), 27-35. http://dx.doi.org/10.1093/chemse/17.1.27

Kupritz, V. W. (1998). Privacy in the work place: the impact of building design. Journal of Environmental Psychology, 18(4), 341-356. http://dx.doi.org/10.1006/jevp.1998.0081

Merriam-Webster. (n.d.). An Encyclopedia Britannica Company. Retrieved from http://www.merriam-webster.com/dictionary/globalization?show=0\&t=1286134710

Oliver, P. (1997). Encyclopedia of vernacular architecture of the world. Cambridge University Press.

Preiser, W. F. (1995). Post-occupancy evaluation: how to make buildings work better. Facilities, 13(11), 19-28. http://dx.doi.org/10.1108/02632779510097787

Reed, R., Bilos, A., Wilkinson, S., \& Schulte, K. W. (2009). International comparison of sustainable rating tools. The Journal of Sustainable Real Estate, 1(1), 1-22.

Silverman, H. (2009, April 15). Perspectives: Sustainability: The S-Word. (Ecotrust). Retrieved from http://www.peopleandplace.net/perspectives/2009/4/15/sustainability_the_s-word

Shafiee, S., \& Topal, E. (2009). When will fossil fuel reserves be diminished? Energy Policy, 37(1), 181-189. http://dx.doi.org/10.1016/j.enpol.2008.08.016

Sundell, J. (2004). On the history of indoor air quality and health. Indoor air, 14(s7), 51-58. http://dx.doi.org/10.1111/j.1600-0668.2004.00273.x

United Nations. (1987, March 20). Report of the World Commission on Environment and Development: Our Common Future. Retrieved from http://www.un-documents.net/wced-ocf.htm

USEPA. (n.d.). Indoor Air Quality. Retrieved from http://www.epa.gov/iaq/pubs/sbs.html

Vijverberg, G. (2002). Accommodation functionality assessment in office buildings. Facilities, 20(3/4), 94-103. http://dx.doi.org/10.1108/02632770210423803

Wilson, E. O. (1984). Biophilia. Cambridge: Harvard University Press.

\section{Notes}

Note 1. "The term "sick building syndrome" (SBS) is used to describe situations in which building occupants experience acute health and comfort effects that appear to be linked to time spent in a building, but no specific illness or cause can be identified... In contrast, the term "building related illness" (BRI) is used when symptoms of diagnosable illness are identified and can be attributed directly to airborne building contaminants" (USEPA, n.d.).

Note 2. Vernacular architecture can be defined as “...comprising the dwellings and all other buildings of the people. Related to their environmental contexts and available resources they are customarily owner or community-built, utilizing traditional technologies. All forms of vernacular architecture are built to meet specific needs, accommodating the values, economies and ways of life of the cultures that produce them" (Oliver, 1997).

\section{Copyrights}

Copyright for this article is retained by the author(s), with first publication rights granted to the journal.

This is an open-access article distributed under the terms and conditions of the Creative Commons Attribution license (http://creativecommons.org/licenses/by/3.0/). 